\title{
EFEK HEAT TREATMENT TERHADAP KEKUATAN IMPACT KOMPOSIT ALAM
}

\author{
Joko Susanto $^{1}$
}

\begin{abstract}
ABSTRAK
Pembuatan komposit polyester-serat nanas dengan komposisi berat serat 2,5\% dan $0 \%$ dengan panjang serat $1 \mathrm{~cm}$ dibuat berdasarkan standart ISO 179-1:2010 telah berhasil dilakukan. Hasil specimen sebelum dilakukan pengujian impact, terlebih dahulu dilakukan annealing selama 24 jam. Hasil pengujian kekuatan impact mengalami peningkatan dengan penambahan proses annealing dan penambahan berat serat.
\end{abstract}

Kata kunci: Kekuatan Impact, Komposit, Serat Nanas, Anneling

\section{PENDAHULUAN}

Perkembangan ilmu pengetahuan dan teknologi memunculkan penemuan-penemuan baru di berbagai bidang. Dunia teknik merupakan salah satu bidang yang menunjukkan perkembangan yang sangat pesat. Terobosan terobosan baru senantiasa dilakukan dalam rangka mencapai suatu hasil yang dapat bermanfaat bagi umat manusia. Salah satu terobosan baru itu adalah teknologi material yang dibuat menjadi sebuah komposit.

Komposit merupakan wujud mendapatkan sifat material baru dengan menggabungkan antara beberapa material yang memiliki sifat saling menguntungkan. Penggabungan dari jenis material yang berbeda sifatnya pada komposit bertujuan untuk mendapatkan material baru yang mempunyai sifat antara material penyusunnya yang tidak akan diperoleh jika material penyusunnya berdiri sendiri.

Material yang menyusun komposit tersebut biasanya seperti fibers, particle, laminate or layers, flakes fillers, dan matrik. Matrik sering disebut sebagai unsur pokok bodi sedangkan fibers, particle, laminate or layers, flakes fillers disebut sebagai unsur pokok struktur. Sifat-sifat yang dapat diperoleh menjadi lebih baik antara lain: kekuatan, kekakuan, ketahanan lelah, ketahanan bending, ketahanan korosi, berat jenis, pengaruh terhadap

\footnotetext{
${ }^{1}$ Prodi S1 Teknik Mesin Fakultas Teknik Universitas Muhammadiyah Semarang, Indonesia.
} 
temperatur, isolasi termal dan isolasi konduktifitas. Tujuan dari penelitian ini adalah untuk mengetahui pengaruh variasi berat serat dan annealing terhadap kekuatan impact komposit polyester-serat nanas.

\section{LANDASAN TEORI}

Penggabungan dari jenis material yang berbeda sifatnya pada komposit bertujuan untuk mendapatkan material baru yang mempunyai sifat antara material penyusunnya yang tidak akan diperoleh jika material penyusunnya berdiri sendiri. Material yang menyusun komposit tersebut biasanya seperti fibers, particle, laminate or layers, flakes fillers, dan matrik. Matrik sering disebut sebagai unsur pokok bodi sedangkan fibers, particle, laminate or layers, flakes fillers disebut sebagai unsur pokok struktur. Sifat sifat yang dapat diperoleh menjadi lebih baik antara lain : kekuatan, kekakuan, ketahanan lelah, ketahanan bending, ketahanan korosi, berat jenis, pengaruh terhadap temperatur, isolasi termal dan isolasi konduktifitas.

Secara umum komposit dapat digolongkan menjadi dua, yaitu berdasarkan matrik dan penguatnya. Berdasarkan matriknya komposit digolongkan menjadi tiga, yaitu:

a. Komposit matrik logam, menggunakan bahan logam sebagai matriknya

b. Komposit matrik polimer, menggunakan bahan sebagai matriknya

c. Komposit matrik keramik, menggunakan bahan keramik sebagai matriknya

Sedangkan menurut unsur penguatnya, digolongkan menjadi tiga, yaitu:

1. Komposit partikel, yaitu penguatnya berbentuk partikel.

Komposit partikel merupakan komposit yang di dalamnya mengandung reinforcement berbentuk partikel - partikel atau serbuk. Komposit jenis ini memiliki beberapa keuntungan yang diperoleh yaitu dapat digunakan untuk meningkatkan kekuatan dan meningkatkan kekerasan material, kekuatannya lebih seragam pada berbagai arah, dan cara penguatan dan pengerasan oleh partikulat adalah dengan menghalangi pergerakan dislokasi. Komposit partikel terdiri dari matrik yang berukuran kecil dengan bentuk butiran-butiran.

Menurut Mahayatra, (2013) komposit partikel merupakan komposit yang di dalamnya berisi bahan penguat berbentuk serbuk. Sifat-sifat komposit partikel dipengaruhi beberapa faktor yaitu ukuran dan bentuk partikel, bahan partikel, rasio perbandingan antara partikel satu dengan yang lain, dan jenis matrik yang digunakan. Keunggulan komposit polimer yang menggunakan partikel yaitu dapat meningkatkan sifat fisis material seperti kekuatan mekanis, dan modulus elastisitas, dan memberikan 
kekuatan komposit lebih homogen (merata).

Beberapa keunggulan lain dari komposit yang disusun oleh reinforcement berbentuk partikel adalah:

a. Kekuatan lebih seragam pada berbagai arah.

b. Dapat digunakan untuk meningkatkan kekuatan dan meningkatkan kekerasan material.

c. Cara penguatan dan pengerasan oleh partikular adalah dengan menghalangi pergerakan dislokasi.

2. Komposit serat (fiber), yaitu penguatnya berbentuk serat.

Fungsi utama dari serat adalah untuk menopang kekuatan komposit itu sendiri, sehingga tinggi rendahnya kekuatan komposit sangat tergantung dari jenis serat yang digunakan, karena tegangan yang dikenakan pada komposit mulanya diterima oleh matrik akan diteruskan oleh serat, sehingga serat akan menahan beban sampai beban maksimum, oleh sebab itu serat harus mempunyai tegangan tarik dan modulus elastisitas yang lebih tinggi dibanding matrik penyusun komposit.

Fiber yang digunakan harus mempunyai syarat sebagai berikut:

a. Harus mempunyai diameter yang lebih kecil dari diameter bulk-nya (matriksnya) tetapi harus lebih kuat dari bulknya.

b. Harus mempunyai tensile strength yang tinggi.

3. Komposit struktur, yaitu penguatnya dengan cara penggabungan material komposit.

Komposit struktural terbentuk oleh reinforce yang memiliki bentuk lembaranlembaran. Berdasarkan strukturnya, komposit struktur dapat dibagi menjadi dua yaitu struktur laminate dan struktur sandwich.

\section{a. Laminate}

Laminate merupakan penggabungan dari dua atau lebih lamina (satu lembar komposit dengan arah serat tertentu) yang membentuk elemen struktur secara integral pada komposit. Proses pembentukan lamina ini menjadi laminate dinamakan proses laminai. Sebagai elemen sebuah struktur, lamina yang serat penguatnya satu arah saja (unidirectionallamina) pada umumnya tidak menguntungkan karena memiliki sifat yang buruk. Maka dari itu struktur komposit dibuat dalam bentuk laminate yang terdiri dari beberapa macam lamina atau lapisan yang diorientasikan dalam arah yang diinginkan dan digabungkan bersama sebagai sebuah unit struktur.

\section{b. Sandwich}

Komposit sandwich merupakan salah satu jenis komposit struktur yang 
sangat potensial untuk dikembangkan saat ini. Komposit sandwich merupakan komposit yang tersusun dari 3 lapisan, lapisan pertama dari flat composite (metal sheet) sebagai kulit permukaan (skin) serta meterial inti (core) di bagian tengahnya (berada diantaranya). Core yang biasa dipakai adalah core import, seperti polyuretan (PU), polyvynil Clorida (PVC), dan honeycomb. Tujuan dibuatnya komposit sandwich yaitu untuk mengefisien berat yang agar lebih optimal, namun mempunyai kekakuan dan kekuatan yang tinggi, sehinggga untuk mendapatkan karakteristik tersebut, pada bagian tengah diantara kedua skin dipasang core. Komposit sandwich merupakan jenis komposit yang sangat cocok untuk menahan beban lentur, impak, meredam getaran maupun suara.

Komposit sandwich akan terbentuk menjadi struktur yang ringan tetapi mempunyai kekakuan dan kekuatan yang tinggi. Biasanya pemilihan bahan untuk komposit sandwich, beberapa syaratnya yaitu ringan, tahan panas dan korosi, serta harga juga dipertimbangkan. karena menggunakan material inti yang sangat ringan, maka akan dihasilkan komposit yang mempunyai sifat kuat, ringan, dan kaku. Komposit sandwich dapat diaplikasikan sebagai struktural maupun non-struktural bagian internal dan eksternal pada pembuatan kereta, bus, truk, dan jenis kendaraan yang lainnya.

\section{Heat Treatment}

Perlakuan panas menurut Mizhar (2011) adalah suatu proses merubah sifat mekanis dengan cara mengubah struktur mikro melalui proses pemanasan dan pengaturan kecepatan pendinginan dengan atau tanpa merubah komposisi kimia yang bersangkutan.

PWHT merupakan proses pemanasan dan pendinginan pada logam untuk mendapatkan sifat-sifat tertentu yang diperlukan untuk suatu konstruksi, misalnya kekuatan, kelunakkan, memperhalus ukuran butir. Terdapat beberapa jenis PWHT diantaranya hardening, tempering, quenching, dan annealing. Perlakuan panas yang tepat dapat menghilangkan tegangan dalam, besar butir dapat diperbesar atau diperkecil, peningkatan ketangguhan atau dapat menghasilkan permukaan yang keras disekeliling inti yang ulet. Menurut Purwaningrum (2006) PWHT mempunyai tiga dasar yaitu heating, holding, cooling. Heating merupakan pemanasan sampai diatas atau dibawah temperatur kritis suatu material. Holding merupakan penahanan material pada temperatur pemanasan untuk memberikan kesempatan perubahan struktur mikro. Cooling merupakan pendninginan dengan kecepatan yang diinginkan.

Secara umum heat treatment dibagi dalam tiga tahap, yaitu:

1. Pemanasan sampai suhu tertentu sesuai dengan proses heat treatment dan dengan 
kecepatan tertentu tergantung dari dimensi dan konduktifitas perpindahan panas bahan.

2. Mempertahankan suhu untuk waktu tertentu, sehingga temperaturnya merata pada seluruh bagian bahan.

3. Pendinginan dengan media pendingin yang bergantung pada proses heat treatment dan bahan yang digunakan. Pada baja karbon rendah dan sedang biasanya digunakan air sebagai media pendingin, karena laju pendinginannya cukup cepat sehingga terbentuk martensit. Sedangkan pada baja karbon tinggi dan baja paduan digunakan minyak sebagai media pendingin dengan laju pendinginan yang lebih lambat.

Menurut Amanto (2003) annealing dapat didefinisikan sebagai pemanasan pada suhu yang sesuai, kemudian diikuti dengan pendinginan pada kecepatan yang sesuai. Hal tersebut mempunyai tujuan untuk menginduksi kelunakan, memperbaiki sifat-sifat pengerjaan dingin, dan membebaskan tegangan-tegangan pada baja sehingga diperoleh struktur yang dikehendaki. Proses annealing pada komposit polyester dilakukan pada suhu antara $80^{\circ} \mathrm{C}$ dan $105^{\circ} \mathrm{C}$, namun lebih disukai pada suhu $85^{\circ} \mathrm{C}$ sampai $100^{\circ} \mathrm{C}$. Sedangkan menurut Purwaningrum (2006) annealing merupakan proses PWHT yang mempunyai tujuan untuk memperbaiki keuletan dan menurunkan tegangan tarik. Annealing dilakukan dengan cara memanaskan material di dalam furnace sampai pada suhu tertentu dan ditahan pada suhu tersebut secara konstan dalam waktu tertentu, pendinginan dilakukan di dalam furnace.

Menurut Dieter (1996) proses annealing merupakan proses perlakuan panas untuk menghasilkan perlit yang kasar (coarse perlite) tetapi lunak dengan pemanasan sampai austenisasi dan didinginkan secara perlahan-lahan dalam tungku pemanas (furnace), dengan tujuan untuk memperbaiki ukuran butir serta dalam beberapa hal juga untuk memperbaiki machin- ibility. Disamping itu juga pelunakan dilakukan untuk tujuan meningkatkan keuletan dan mengurangi tegangan dalam yang meyebabkan material berprilaku getas.

Perlu diketahui bahwa untuk melakukan proses annealing penuh dilakukan sebelum dimulainya proses pengerjaan dingin. Selain annealing penuh ada juga annealing isothermal (annealing tak sempurna). Annealing isothermal adalah proses annealing dengan pemanasan antara temperatur kritis bawah dan temperatur kritis atas. Pada proses ini yang terjadi adalah semua austenit berubah menjadi perlit. Annealing yang terakhir adalah Annealing kritis bawah. Proses ini dapat didefinisikan sebagai pemanasan yang dipertahankan pada beberapa suhu di bawah batas transformasi (perubahan), diikuti dengan proses pendinginan pada kecepatan yang sesuai. Proses ini diintroduksi secara sangat luas selama pelaksanaan pengerjaan dingin agar menghilangkan perubahan bentuk dari kristal (Amanto, 2003). 


\section{Kekuatan Impact}

Pengujian impact adalah suatu metode yang digunakan untuk menguji kekuatan suatu bahan/material dengan cara pemberian beban gaya yang satu sumbu. Pengujian impact menurut Malau (2008), mempunyai tujuan untuk mengetahui kemampuan spesimen menyerap energi yang diberikan. Pengujian impact merupakan salah satu proses pengukuran terhadap sifat kerapuhan bahan. Sifat keuletan atau toughness dari suatu bahan yang tidak dapat terdeteksi oleh pengujian lain, jika dua buah bahan akan memiliki sifat yang hampir sama akan tetapi jika diuji dengan impact test maka hasilnya akan berbeda karena sedikit selisih nilai atau komposisi bahan akan menyebabkan hasil uji yang berbeda. Pengujian impact bertujuan untuk mengetahui kekuatan bahan terhadap pemberian beban kejut (shock resistance), seperti kerapuhan yang disebabkan oleh perlakuan panas atau sifat kerapuhan dari produk tuangan (Casting) serta pengaruh bentuk dari produk tersebut.

Pengujian impact merupakan respon yang diterima terhadap beban kejut atau beban tiba-tiba. Pengujian ini dilakukan dengan mesin uji impact yang dirancang dengan memilki sebuah pendulum dengan berat tertentu yang mengayun dari suatu ketinggian untuk memberikan beban kejut, dalam pengujian ini terdapat dua macam cara pengujian, yaitu cara "Izod" dan cara "Charpy" yang berbeda menurut arah pemberian beban terhadap bahan uji serta kedudukan bahan uji (Sudjana, 2008). Pada mesin penguji impact charpy, pengujian yang dilakukan masih mengunakan (notch toughness) atau disebut juga sebagai takik untuk pengukuran energi impact. Spesimen charpy berbentuk batang dengan penampang lintang bujur sangkar dengan takik V yang dibuat melalui proses permesinan. Pada pengujian impact charpy, energi yang diserap oleh benda uji biasanya dinyatakan dalam satuan Joule dan dibaca langsung pada skala (deal) sesuai petunjuk yang telah dikalibrasi yang terdapat pada mesin penguji (Yuwono, 2009).

Pemberian beban dalam proses pengujian pukul takik (impact test), diberikan oleh ayunan pendulum dengan berat $\mathrm{G}$ dan jarak terhadap sumbu putar $\mathrm{R}$ yang bergerak dari ketinggian h1 pada sudut awal $\alpha$. 

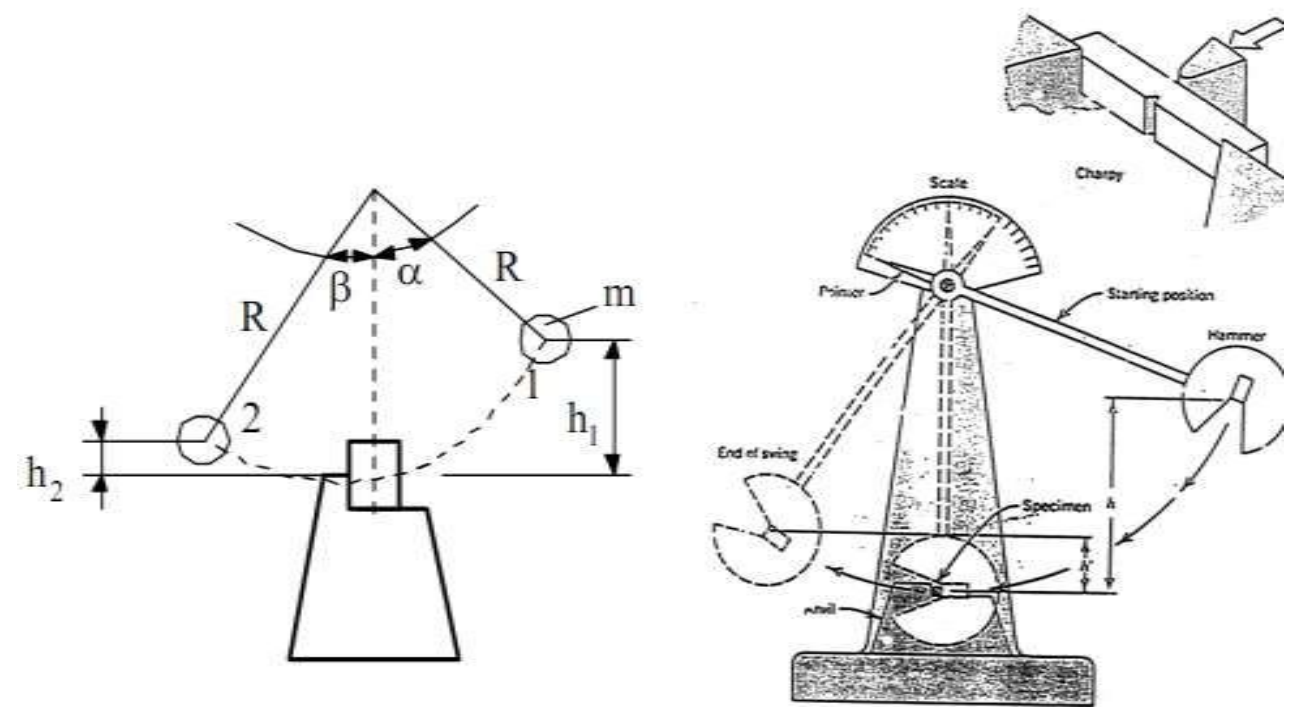

Gambar 1. Ilustrasi Skematis Pengujian Impact Charpy (Umam, 2015)

Pada pengujian impact, energi yang diserap untuk mematahkan benda uji harus diukur. Setelah bandul dilepas dan megenai spesimen uji, maka spesimen uji akan patah, setelah itu bandul akan berayun kembali, semakin besar energi yang terserap, semakin rendah ayunan kembali dari bandul. Energi terserap biasanya dapat terbaca langsung pada skala penunjuk yang sudah terkalibrasi yang terdapat pada mesin penguji. Energi terserap juga dapat dituliskan dalam persamaan 2.1 :

E serap $=$ Energi awal - Energi yang tersisa

$$
\begin{aligned}
& \mathrm{m} \cdot \mathrm{g} \cdot \mathrm{h}_{1}-\mathrm{m} \cdot \mathrm{g} \cdot \mathrm{h}_{2} \\
= & \mathrm{m} \cdot \mathrm{g}(\mathrm{R} \cdot \cos \beta)-(\mathrm{R} \cdot \cos \alpha)
\end{aligned}
$$

$$
\text { E serap }=\text { m.g. R. }(\cos \beta-\cos \alpha) \quad \text { (Putra, 2017) }
$$

Dimana :

$$
\begin{aligned}
& \mathrm{E}=\text { energi terserap }=\text { tenaga untuk mematahkan benda uji (Joule) } \\
& \mathrm{m}=\text { massa pendulum }(\mathrm{kg}) \\
& \mathrm{g}=\text { percepatan gravitasi }\left(\mathrm{m} / \mathrm{s}^{2}\right)=10 \mathrm{~m} / \mathrm{s}^{2} \\
& \mathrm{~h} 1=\text { tinggi jatuh palu godam }(\mathrm{m})=\mathrm{R}+\mathrm{R} \sin (\alpha-90) \\
& \mathrm{h} 2=\text { tinggi ayunan palu godam }(\mathrm{m})=\mathrm{R}+\mathrm{R} \sin (\beta-90) \\
& \mathrm{R}=\text { jarak titik putar ke titik berat palu godam }(\mathrm{m}) \\
& \alpha=\text { sudut jatuh sebelum ayunan }\left(^{\circ}\right) \\
& \beta=\text { sudut ayun setelah mematahkan spesimen }\left(^{\circ}\right)
\end{aligned}
$$




\section{METODOLOGI}

\section{Bahan Penelitian}

- Resin Yukalac 157 BQTN-EX Series

- Katalis MEPOXE Type A

Penggunaan katalis MEPOXE Type A sebanyak $1 \%$ sebagai pengeras komposit serat alam.

- Serat daun nanas

$-\mathrm{NaOH}$

- Air

- Wax
Alat Penelitian
a. Cetakan specimen uji Impact
b. Alat Uji Impact GOTECH GT-7045-MD
c. Timbangan Digital
d. Amplas
e. Gunting

\section{Pembuatan Spesimen}

a. Pemilihan Serat dan Perlakuan $\mathrm{NaOH}$

Proses pemilihan serat daun nanas dimulai dengan menyiapkan serat daun nanas yang warnanya sama dan tebalnya serat sama seperti terlihat pada Gambar 1 (a), kemudian dicuci dengan air bersih untuk menghilangkan kotoran - kotoran yang menempel pada serat. Setelah itu serat direndam dengan $\mathrm{NaOH}$ yang telah dilarutkan dalam air bersih. Prosentase komposisi $\mathrm{NaOH}$ adalah 30\% dan air bersih 70\% seperti terlihat pada Gambar 2 (b).

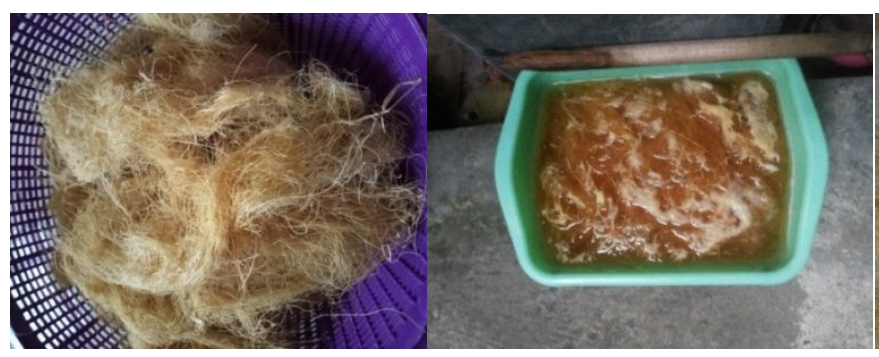

(a) (b)

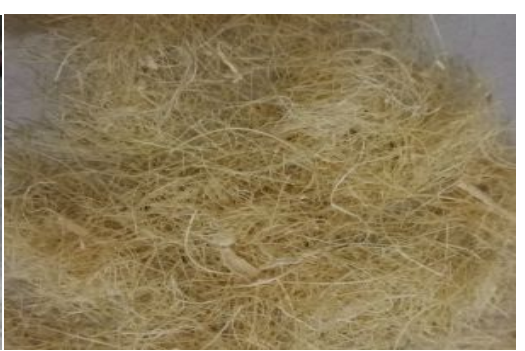

(c)

Gambar 3. Proses Perlakuan $\mathrm{NaOH}$ 


\section{Diagram Alur Penelitian}

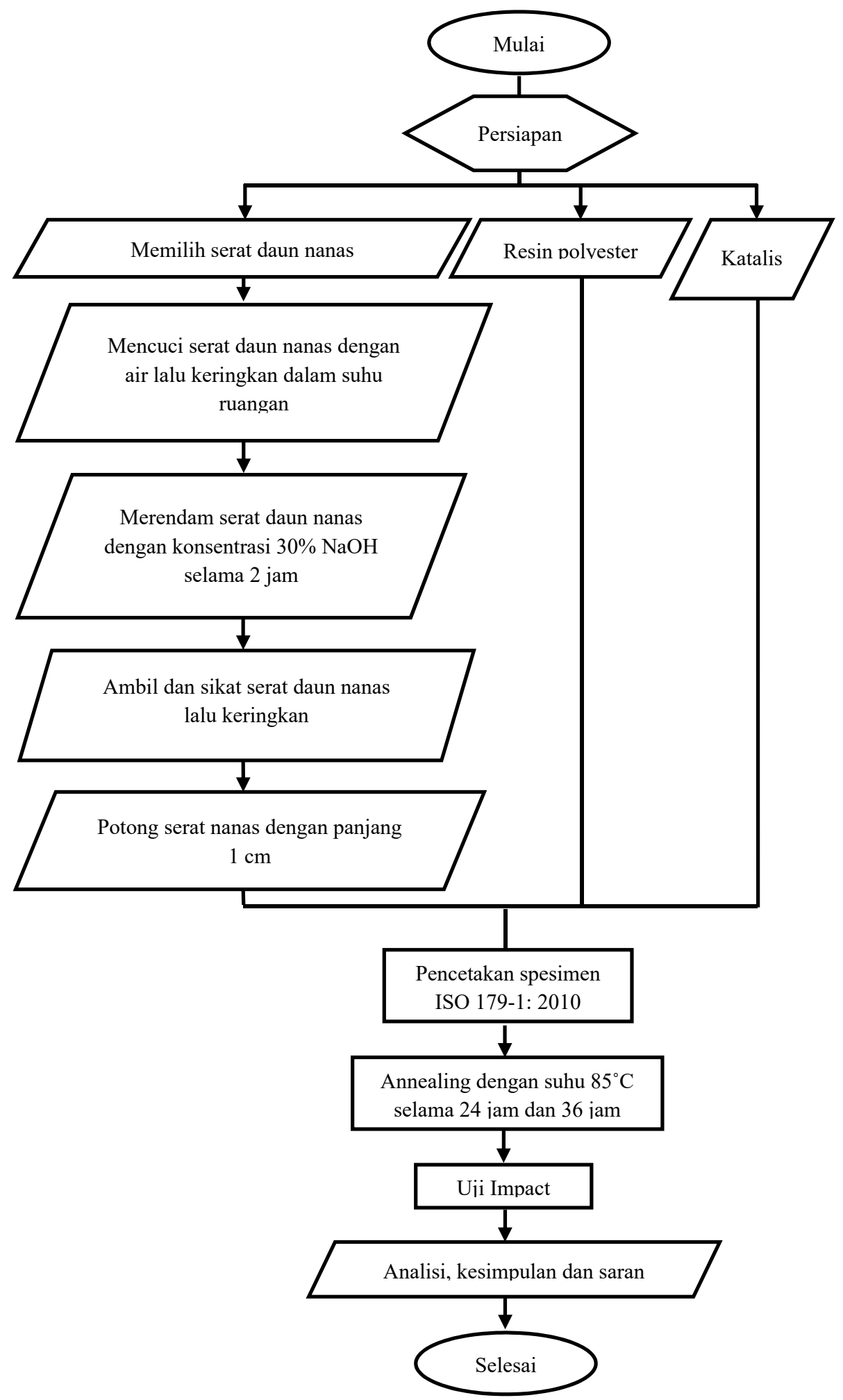

Gambar 3. Diagram Alur Penelitian 
Perendaman $\mathrm{NaOH}$ dilakukan selama 2 jam, kemudian serat ditiriskan dan dibilas dengan air mengalir agar sisa - sisa $\mathrm{NaOH}$ dan kotoran yang masih menempel hilang. Perendaman dengan larutan $\mathrm{NaOH}$ bertujuan untuk mengurangi kandungan lignin dan kotoran yang ada pada serat. Pada penelitian sebelumnya juga menyatakan bahwa perlakuan $\mathrm{NaOH} 30 \%$ selama 2 jam mampu meningkatkan kekuatan tarik komposit serat nanas. Setelah serat bersih kemudian dikeringkan dengan suhu ruang selama 4-5 hari hingga benar-benar kering. Setelah kering serat dipotong menggunakan gunting dan diukur menggunakan penggaris dengan panjang $1 \mathrm{~cm}$.

b. Pembuatan Spesimen

Proses pembuatan specimen dilakukan dengan pencetakan dengan cara cetakan specimen diolesi tipis-tipis dengan wax agar mudah saat pelepasan specimen, kemudian mencampur resin, katalis, dan serat nanas yang sudah ditimbang ke dalam satu wadah cawan dan diaduk hingga homogen, kemudian dituangkan ke dalam cetakan. Setelah itu diamkan pada suhu ruang selama kurang lebih 24 jam hingga specimen kering. Untuk melepas specimen yang sudah kering dari cetakanya digunakan plat untuk mendorong specimen sampai terlepas.

Specimen uji impact dibuat berdasarkan standart ISO 179-1:2010 seperti pada Gambar 4.

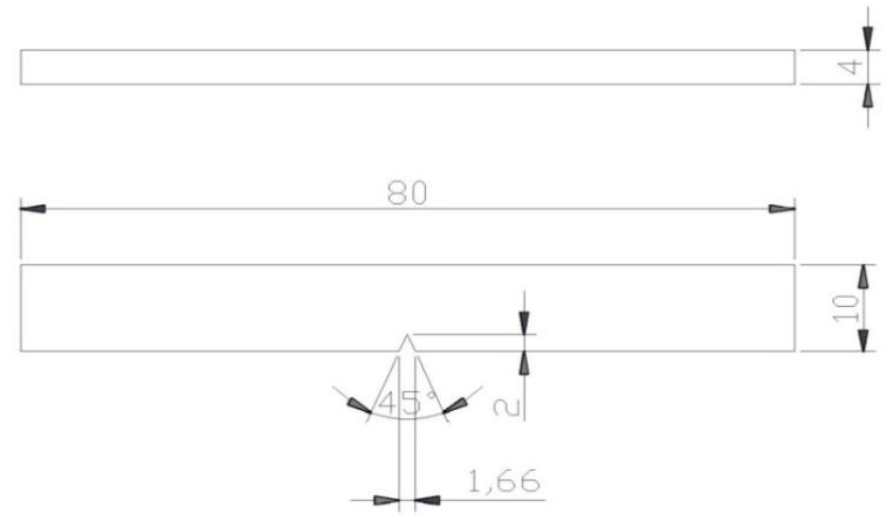

Gambar 4. Ukuran standart ISO 179-1:2010

c. Annealing

Penambahan perlakuan variasi annealing yaitu dengan cara specimen dipanaskan di dalam oven pemanas dengan suhu konstan $85^{\circ} \mathrm{C}$ selama 24 jam dan specimen lainya selama 36 jam seperti terlihat pada Gambar 5. Perlakuan annealing bertujuan untuk menambah kekuatan pada komposit itu sendiri. 


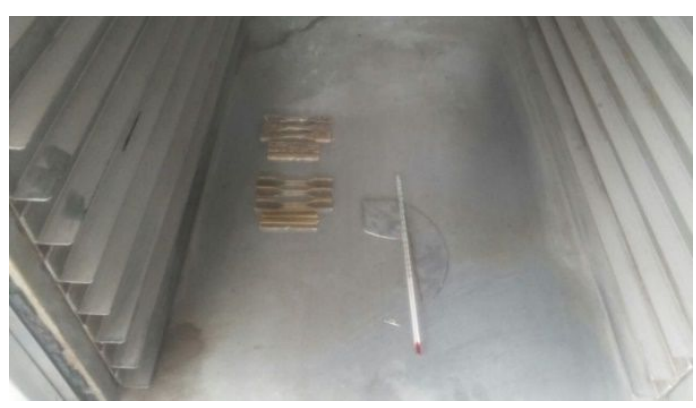

Gambar 5. Annealing specimen di dalam oven

\section{HASIL DAN PEMBAHASAN}

Proses pengujian impact menggunkanan alat GOTECH GT-7045-MD dan jumlah specimen untuk proses pengujian impact sebanyak 12 spesimen. Gambar 6 dan 7 merupakan gambar specimen standart ISO 179-1:2010 dengan berat serat dan perlakuan aniling yang berbeda yaitu berat serat $0 \%$ dengan perlakuan annealing selama 24 jam seperti terlihat pada Gambar 6(a), berat serat 0\% dengan perlakuan annealing selama 36 jam seperti terlihat pada Gambar 6(b), berat serat 2,5\% dengan perlakuan annealing selama 24 jam seperti terlihat pada Gambar 6(a), dan berat serat 2,5\% dengan perlakuan annealing selama 36 jam seperti terlihat pada Gambar 6(b).

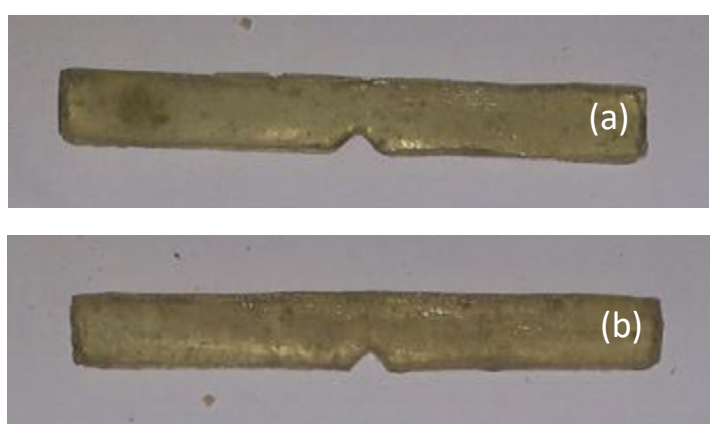

Gambar 6. Spesimen Uji Impact dengan berat serat 0\% dengan annealing (a) 24 jam (b) 36 jam

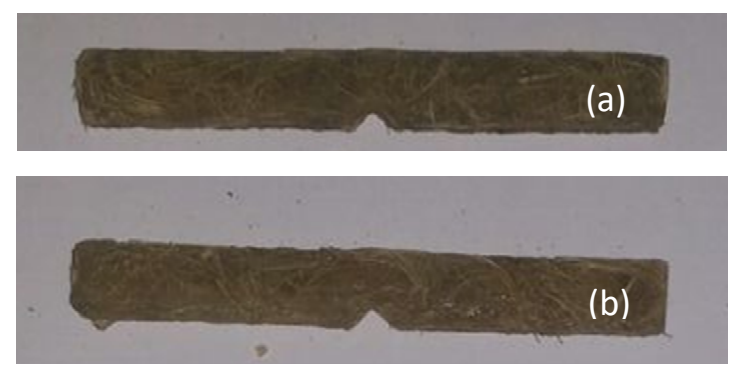

Gambar 7. Spesimen Uji Impact dengan berat serat 2,5\% dengan annealing (a) 24 jam (b) 36 jam 
Berdasarkan hasil pengujian impact yang dilakukan di laboratorium teknik mesin Universitas Negeri Semarang dengan pengamatan pada variasi berat serat dan perlakuan annealing yang berbeda yaitu berat serat $0 \%$ dengan perlakuan annealing selama 24 jam dan 36 jam, dan berat serat 2,5\% dengan perlakuan annealing selama 24 jam dan 36 jam diperoleh hasil seperti pada Tabel 1.

Tabel 1. Hasil Pengujian Impact

\begin{tabular}{cccccc}
\hline No. & $\begin{array}{c}\text { Kode } \\
\text { Spesimen }\end{array}$ & $\begin{array}{c}\text { Berat serat } \\
(\mathbf{w t .} \%)\end{array}$ & $\begin{array}{c}\text { Lamanya Perlakuan } \\
\text { Annealing (jam) }\end{array}$ & $\begin{array}{c}\text { E } \\
(\mathbf{J})\end{array}$ & $\begin{array}{c}\text { HI } \\
(\mathbf{J} / \mathbf{m m} \mathbf{)})\end{array}$ \\
\hline $\mathbf{1}$ & A & 0 & 24 & 0,3033 & 0,0108 \\
\hline $\mathbf{2}$ & B & 0 & 36 & 0,3267 & 0,0105 \\
\hline $\mathbf{3}$ & C & 2,5 & 24 & 0,3600 & 0,0129 \\
\hline $\mathbf{4}$ & D & 2,5 & 36 & 0,3633 & 0,3633 \\
\hline
\end{tabular}

\section{Energi Fracture}

Berdasarkan hasil pengujian impact yang dilakukan dengan pengamatan pada Energi Fracture didapatkan hasil yang berbeda, yaitu nilai rata-rata Energi Fracture pada specimen menggunakan berat serat 2,5\% dan perlakuan annealing selama 36 jam yaitu 0,3633 Joule, specimen menggunakan berat serat $0 \%$ dan perlakuan annealing selama 36 jam yaitu 0,3267 Joule, specimen menggunakan berat serat 2,5\% dan perlakuan annealing selama 24 jam yaitu 0,3600 Joule, dan specimen menggunakan berat serat $0 \%$ dan perlakuan annealing selama 24 jam yaitu 0,3033 Joule.

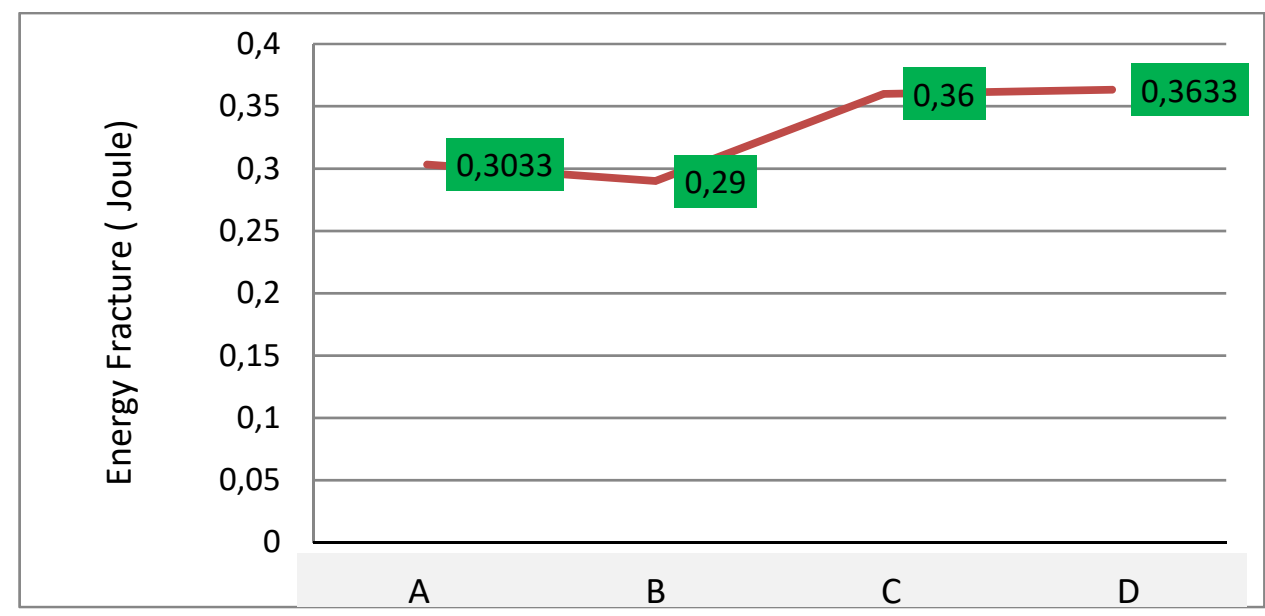

Gambar 8. Grafik Nilai Rata-Rata Energi Fracture 


\section{Kekuatan Impact}

Berdasarkan hasil pengujian impact yang dilakukan dengan pengamatan pada Kekuatan Impact didapatkan hasil yang berbeda, yaitu nilai rata-rata Kekuatan Impact pada specimen menggunakan berat serat 2,5\% dan perlakuan annealing selama 36 jam yaitu $0,0130 \mathrm{~J} / \mathrm{mm}^{2}$, specimen menggunakan berat serat $0 \%$ dan perlakuan annealing selama 36 jam yaitu $0,0105 \mathrm{~J} / \mathrm{mm}^{2}$, specimen menggunakan berat serat $2,5 \%$ dan perlakuan annealing selama 24 jam yaitu $0,0129 \mathrm{~J} / \mathrm{mm}^{2}$, dan specimen menggunakan berat serat $0 \%$ dan perlakuan annealing selama 24 jam yaitu $0,0108 \mathrm{~J} / \mathrm{mm}^{2}$.

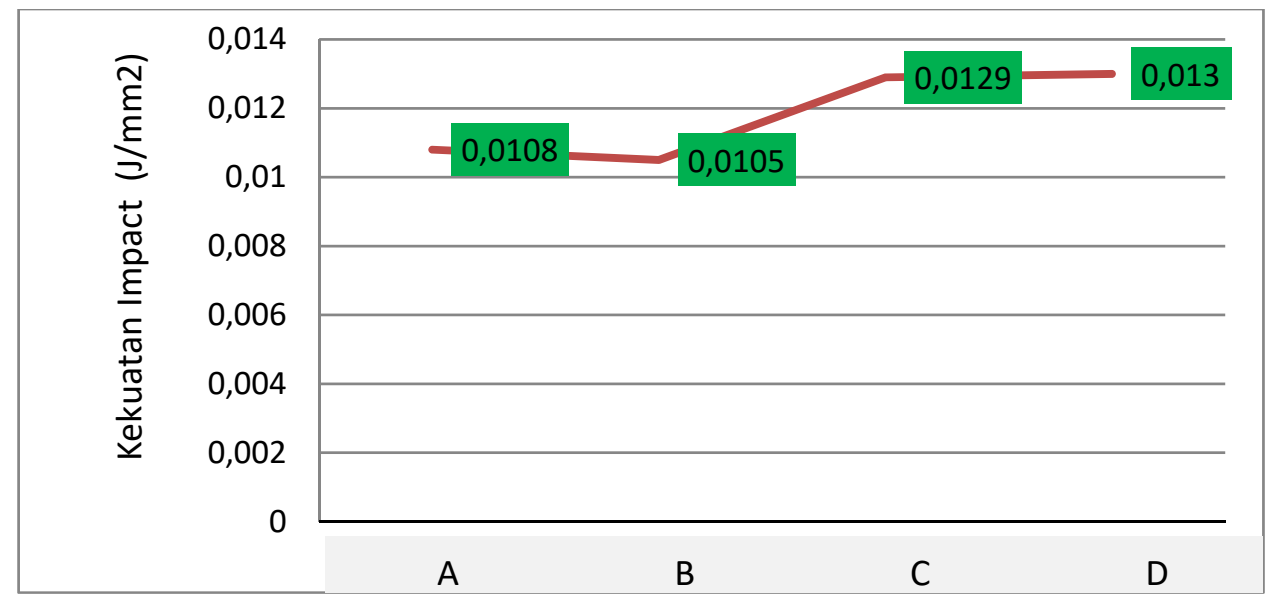

Gambar 9. Grafik Nilai Rata-Rata Kekuatan Impact

Kecenderungan dengan adanya penambahan berat serat dan penambahan lamanya waktu annealing pada komposit polyester-serat nanas menghasilkan kekuatan impact yang makin besar, namun kekuatan tarik yang rendah (Susanto J, 2018). Salah satu penyebab rendahnya kekuatan tarik komposit setelah dilakukan perlakuan alkali adalah lama perendaman serat di dalam larutan $\mathrm{NaOH}$ yang terlalu lama sehingga dapat membuat serat menjadi rapuh (Amin M, 2012).

\section{KESIMPULAN}

Hasil pengujian impact rata - rata menunjukkan nilai kekuatan impact mengalami peningkatan seiring dengan penambahan proses annealing dan penambahan berat serat. Komposit polyester-serat nanas dengan komposisi serat $0 \%$ dengan proses annealing selama 24 jam memiliki kekuatan impact rendah yaitu 0,0108 J/mm2. Sedangkan nilai kekuatan impact tertinggi yaitu $0,3633 \mathrm{~J} / \mathrm{mm} 2$ dengan komposisi serat $2,5 \%$ dengan proses annealing selama 36 jam, namun memiliki kekuatan tarik terendah yaitu 16,8 N/mm². Kekuatan impact 
komposit polyester-serat nanas tertinggi yaitu $0,3633 \mathrm{~J} / \mathrm{mm} 2$ dengan komposisi serat 2,5\% dan proses annealing selama 36 jam.

\section{DAFTAR PUSTAKA}

Amanto, Hari, dan Daryanto. 2003. Ilmu Bahan. Jakarta: PT. Bumi Aksara.

Amin M, 2012, Pengaruh Perlakuan Alkali terhadap Kekuatan Tarik Komposit Rambut Manusia, Proseding Seminar Nasional LPPM UNIMUS ISBN: 978-602-18809-0-6_Tgl. 15 Agustus 2012. https:/jurnal.unimus.ac.id/index.php/psn12012010/article/view/534, www.muhamin.com.

Dieter. 1996. Metalurgi Mekanik. Jakarta: Erlangga

Mahayatra, Gede I, Harnowo S dan Savetlana S, 2013, Pengaruh Variasi Panas Quench dan Temper Terhadap Laju Keausan.

Malau, Viktor dan Adhika Widyaparaga. 2008. Pengaruh Perlakuan Panas Quench dan Temper Terhadap Laju Keausan, Ketangguhan Impak,kekuatan tarik dan kekerasan baja XW 42 untuk keperluan Cetakan Keramik. Jurnal Media Teknik. No 2. Hal: 186192.

Mizhar, Susri dan Suherman. 2011. Pengaruh Perbedaan Kondisi Tempering Terhadap Struktur Mikro dan Kekerasan dari Baja AISI 4140. Jurnal Dinamis. Vol II. No. 8. Hal: 21-26.

Purwaningrum,Yustiasih. 2006. Karakterisasi Sifat Fisis dan Mekanis Sambungan Las SMAW Baja A-287 Sebelum dan Sesudah PWHT. Jurnal TEKNOIN. Vol. 11, No. 3. Hal: 233-242.

Sudjana, Hardi. 2008. Teknik Pengecoran Logam, Jakarta: Direktorat Pembinaan Sekolah Menengah Kejuruan.

Yuwono, Akhmad Herman. 2009. Buku Panduan Praktikum Karakteristik Material 1 Pengujian Merusak (Destructive testing). Departemen Metalurgi dan Material Fakultas Teknik Universitas Indonesia. Jakarta. 